\title{
Correction to: Springback behaviors of extruded 6063 aluminum profile in subsequent multi-stage manufacturing processes
}

\author{
Zhiwen Liu ${ }^{1,2} \cdot$ Luoxing $\mathrm{Li}^{3} \cdot$ Guan Wang ${ }^{4} \cdot$ Jingran Chen ${ }^{1} \cdot \mathrm{Yi} \mathrm{Jie}^{3}$ \\ Published online: 4 July 2020 \\ (C) Springer-Verlag London Ltd., part of Springer Nature 2020
}

\section{Correction to: The International Journal of Advanced Manufacturing Technology} https://doi.org/10.1007/s00170-020-05551-z

The original article contained a mistake.

In Fig. 8, the characteristic lines were disorderly arranged.

The correct image of Fig. 8 is shown below:

The original article has been corrected.

The online version of the original article can be found at https://doi.org/ $10.1007 / \mathrm{s} 00170-020-05551-\mathrm{z}$

\section{Zhiwen Liu \\ liuzhiwen1008@163.com \\ Guan Wang \\ Belonging1024@163.com}

1 School of Mechanical Engineering, University of South China, Hengyang 421001, China

2 Cooperative Innovation Center for Nuclear Fuel Cycle Technology and Equipment, University of South China, Hengyang 421001, China

3 State Key Laboratory of Advanced Design and Manufacture for Vehicle Body, Hunan University, Changsha 410082, China

4 College of Mechanical Engineering, Ningxia University, Yinchuan 750021, China 
Fig. 8 The AE profile contour of von Mises stress during rotary draw bending

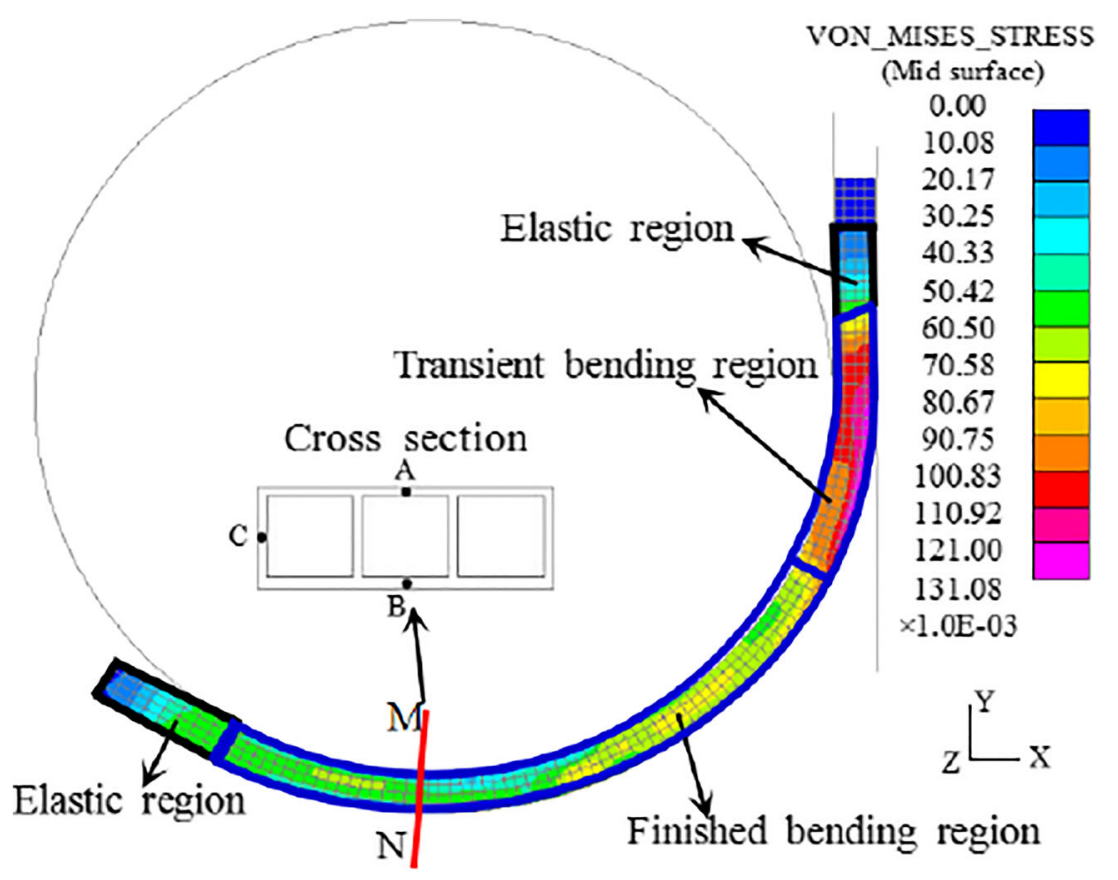

Publisher's note Springer Nature remains neutral with regard to jurisdictional claims in published maps and institutional affiliations. 